patient was readmitted as an emergency because of vomiting, drowsiness, and dyspnea, and he died soon after arrival. Autopsy revealed bilateral tension pneumothorax, diffuse bronchiectatic cavities, and generalized congestion of meningeal vessels. Histologically the lungs and spleen were infiltrated by Langerhans cells. The cerebellum showed focal gliosis associated with Purkinje cell loss. (Polizzi A, Coghill S, McShane MA, Squier W. Acute ataxia complicating Langerhans cell histiocytosis. Arch Dis Child February 2002;86:130-131). (Respond:

Dr A Polizzi, Department of Paediatrics, University of Catania, Via S Sofia, 78, I-95123 Catania, Italy).

COMMENT. The diagnosis of Langerhans' cell histiocytosis (LCH) is made by the electron micrograph finding of Birbeck granules, membranous cytoplasmic structures, $200-400 \mathrm{~nm}$ in width and shaped like tennis rackets, and CD1a and S100 protein antigen on the cell surface (Faquin WC. In case-report. Clinicopathological Exercise. N Engl I Med February 14, 2002;346:513-520). The presentation is usually as bone lesions and dermatitis, hepatosplenomegaly, iymphadenopathy, pancytopenia, fever, and weight loss. CNS manifestations are rarely cerebellar, and usually present with diabetes insipidus from hypothalamic or pituitary infiltration. In the rare cases of cerebellar involvement cited in the pediatric literature, symptoms were chronic and progressive and presented years after LCH diagnosis. The absence of cerebellar infiltration supports a paraneoplastic syndrome and immune mediated mechanism. In the above case report, the primary LCH location was lung involvement. In the $\mathrm{N}$ Engl J Med report (Feb 14, 2002), the primary location of $\mathrm{LCH}$ was a retro-orbital spenoid sinus mass, and the presenting symptom was frontal pain (see below in Headache section).

\title{
CEREBELLAR HEMANGIOBLASTOMA AND VON HIPPEL-LINDAU DISEASE
}

Six pediatric patients with cerebellar hemangioblastoma were screened for germline or somatic mutations of the von Hippel-Landau gene, in a study at Stanford University Medical Center, Palo Alto, CA. Two testing positive for mutations had a history of clinical manifestations of von Hippel-Lindau disease, whereas 4 testing negative had solitary hemangioblastoma and no history of the disease. These solitary cases may involve a molecular process unrelated to the von Hippel-Lindau tumor suppressor pathway. (Fisher PG, Tontiplaphol A, Pearlman EM et al. Childhood cerebellar hemangioblastoma does not predict germline or somatic mutations in the von Hippel-Lindau tumor suppressor gene. Ann Neurol February 2000;51:257-260). (Respond: Dr Paul G Fisher, Room A343, Department of Neurology, Stanford University Medical Center, 300 Pasteur Drive, Palo Alto, CA 94305).

COMMENT. Hemangioblastoma is a rare intracranial tumor, accounting for less than $0.5 \%$ of all pediatric brain tumors (Ries et al, 2001). The apparent absence of von Hippel-Lindau (VHL) gene abnormalities in childhood sporadic cerebellar hemangioblastoma indicates an alternative mechanism of tumorigenesis from that in adults. In 3 reports including 50 adult cases of sporadic cerebellar hemangioblastoma cited by the authors, about $50 \%$ of patients screened had somatic VHL gene mutations. VHL disease is familial with dominant inheritance and manifested by malignant and benign neoplasms of eyes, kidneys, adrenal glands, spine, and brain. The VHL gene is a tumor suppressor gene located on chromosome 3 p25-26. 